\title{
Matrix model of controlling management decisions
}

\author{
Aleksey Parshukov ${ }^{1,}$, , Valery Potemkin ${ }^{3}$, Igor Aleksandrov ${ }^{1}$ and Marina Fedorova ${ }^{2}$ \\ ${ }^{1}$ Peter the Great St. Petersburg Polytechnic University, Polytechnicheskaya 29, St. Petersburg, \\ 195251, Russia \\ ${ }^{2}$ Petrozavodsk State University, Lenina 33, Petrozavodsk, 185910, Russia \\ ${ }^{3}$ St. Petersburg State University of Economics, Sadovaya street 21, St. Petersburg, 191023, Russia
}

\begin{abstract}
The article proposes the structure of the information and software environment of controlling managerial decisions and indicators that affect them. In particular, it describes: 1) a point model that allows you to analyze management decisions in conditions of a matrix functional structure for several branches (if any), functional areas and project groups simultaneously, 2) a system of indicators for fixing management decisions that allows you to create a database of management decisions, as well as maps of management decisions that reflect their content and correlating indicators, 3) model with factors of different influence on the process of making and implementation of managerial decisions, which can consist of a different number of indicators, 4) matrix model of controlling, which integrates all the models into a single system. Creation of controlling system of managerial decisions allows: to unite all types of managerial decisions into a single base, to avoid their inconsistency with each other, to keep centralized records of all indicators of external and internal environment and assess their impact on the implementation of managerial decisions, continuity of all data, transparency and convenience of control, possibility of prompt response to any deviations.
\end{abstract}

\section{Introduction}

Recently, specialists and scientists in the theory and practice of management pay more and more attention to systems of control and support of management decisions.

This is facilitated by the following circumstances:

- increased instability of the external environment, the need to increase the speed of the enterprise's response to its changes,

- the need for continuous monitoring of changes in the external environment,

- complication of organizational systems and mechanisms of enterprise management, the need for better coordination and interaction of all elements of the enterprise,

- surplus of information of different nature, the need to quickly obtain the relevant information from the internal and external environment through the construction of a special information system,

\footnotetext{
* Corresponding author: flowprof@gmail.com
} 
- improvement of quality of accepted administrative decisions by means of observance of special methods, increase of management culture,

- the natural development of science and management theory.

Nowadays, the term controlling is associated with direct management support. It is associated with tasks - consulting, coordination, control, provision of necessary information, assistance in management and decision making..

In modern scientific research attention is paid to the study of the following aspects of controlling.

Controlling technologies as a way of buffering negative impacts of external disturbances on financial and economic sustainability of enterprises [1].

Controlling Big Data to introduce digital technologies into management processes, controlling systems, to get fast and accurate information. Controlling Big Data allows the creation of new business models, proper analysis of customer behavior, facilitates risk and financial management of the company, optimizes processes occurring inside the enterprise $[2]$.

The effect of controlling on organisational performance through the impact on job performance of managers and employees [3].

Recently, the possibility of organization of self-controlling as a new stage of development of the concept of controlling has been actively studied, in particular, special attention is paid to it by $\mathrm{P}$. Horvath [4].

As a system of integrated information support, planning and control activities of the enterprise [5].

As a holistic concept of economic management of the enterprise, aimed at finding out all the chances and risks associated with profit [6].

We consider that controlling should provide efficiency of acceptance and realization of the administrative decisions, as N. Luman notes than what can happen in the future depends on the decision which should be taken in the present [7].

Modern demands of controlling are impossible without information technology support $[8,9]$.

\section{Point model of controlling management decisions}

The models presented below are the results of a major study of management systems of industrial enterprises, carried out as part of the preparation of a $\mathrm{PhD}$. This study is devoted to the coordination of enterprise management system based on the concept of controlling. The proposed models can serve as a conceptual basis for the development of an automated information system to support the management process.

As a basis we took the management system of industrial enterprises, which is characterized by particularly high complexity - production, marketing, finance and accounting, personnel, logistics, sales and other functional areas, a large number of management decisions. Under a management decision we understand a volitional effort, carried out by the subject of management within his official powers and competencies in order to achieve the objectives of the management object and the organization as a whole, formalized in the form of an order or instruction, which has a broad impact on the functioning of the management object, affecting related objects.

It should also be noted the detailing of management decisions on the whole enterprise, on individual units, on functional areas, on individual projects and processes.

If the enterprise uses a matrix management system, organizational structure with double subordination, in this case the process of enterprise management becomes even more complex. 
To improve the efficiency of the process of making and implementing managerial decisions in such conditions, the structure of information and software environment of controlling managerial decisions is proposed.

It is based on a three-dimensional point model of controlling of managerial decisions, which includes managerial decisions on 3 levels - on the project, on the functional area, on the geographical location of the subject of management - a branch. At the same time, such a system allows assessing the correlation of managerial decisions with each other (Fig. 1).

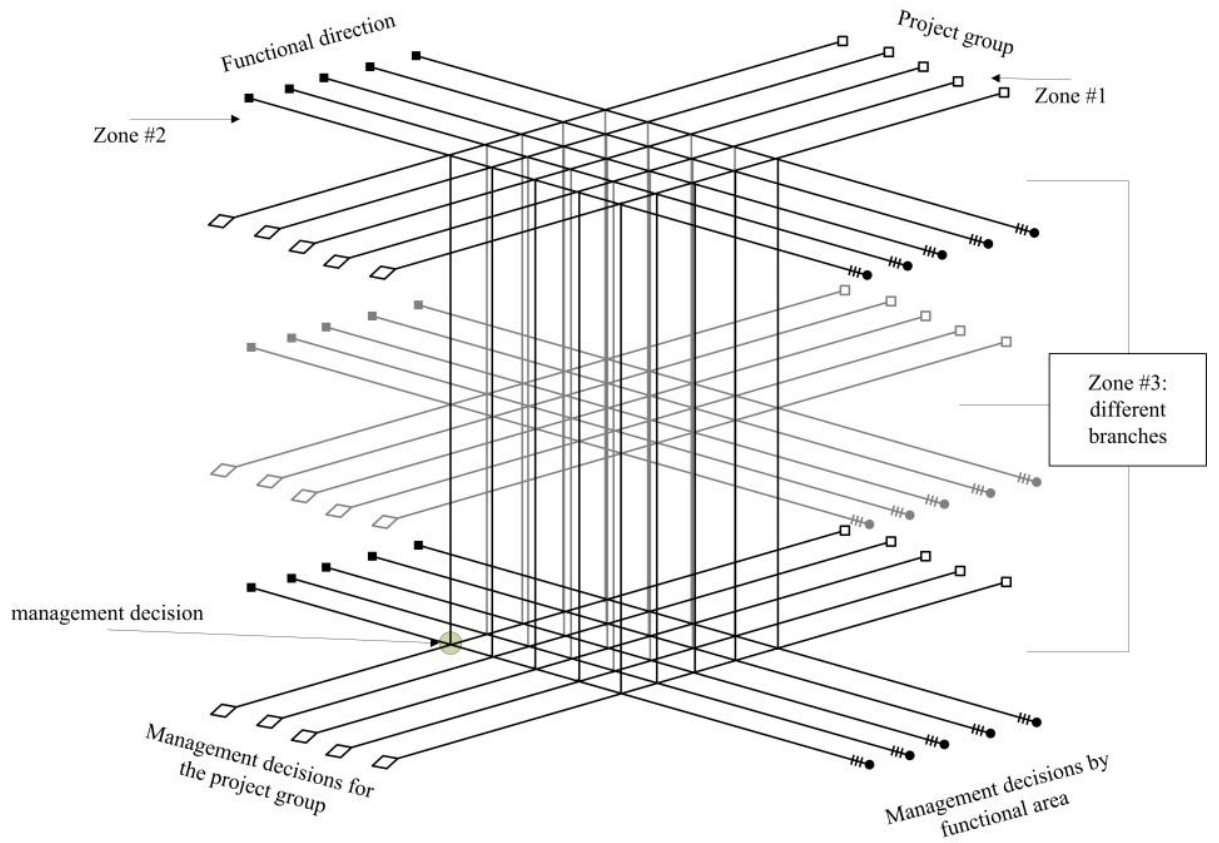

Fig. 1. Point model of controlling management decisions.

The scheme is an abstract model and does not reflect a specific situation.

Lines of zone \#1 represent management decisions of local level (by department, by project group, etc.), lines of zone \#2 are management decisions by functional directions, which may affect the work of several departments or project units, zone \#3 is a sector of territorial unit - a branch. A point in the scheme is a conditional management decision (that is why the model is called a point model), management decisions are represented here by a flow (lines), intersection points of the flows are correlation zones, they are an array of data on a particular area of management decisions and may contain many of them. The lines (management decisions) are transversal throughout the scheme, i.e. the management decision made in the functional direction of "marketing" can affect the existing orders in several project groups, which should be monitored.

Such a view on the system of controlling of managerial decisions allows to open the possibility to correct such problems as inconsistency of managerial decisions to each other, obsolescence, ignoring the previously made, unreasonableness. Such models are created by specialists on the basis of OLAP-technologies that allow to form multidimensional data arrays, which can be superimposed on the project groups formed in the information and communication structure.

This model shows the conditional spatial location of the management decision, as well as allows to link certain data to certain management decisions. Here is an example of a system of indicators for fixing management decisions in an enterprise management system for a matrix organizational structure (see Table 1). 
Table 1. System of indicators for fixing management decisions.

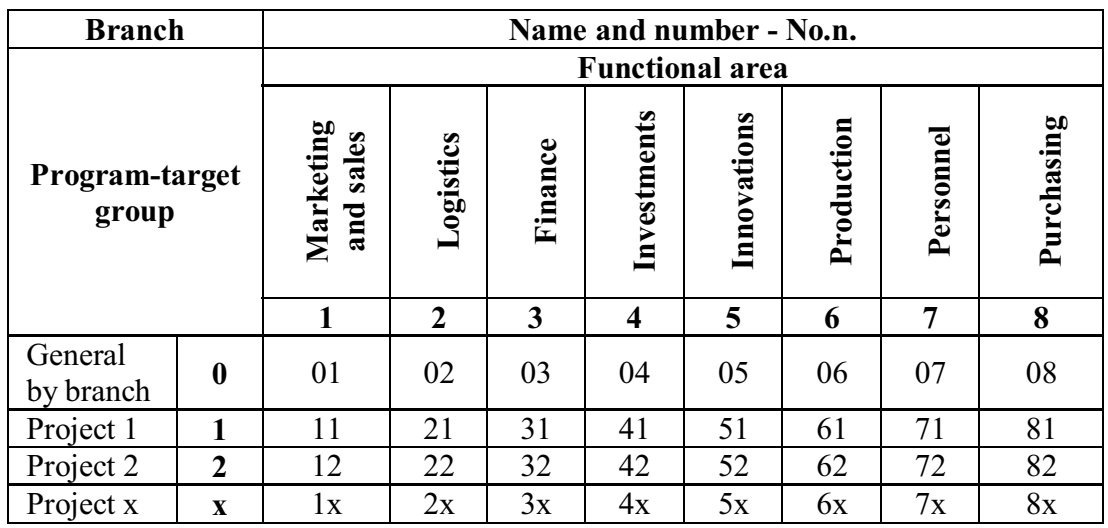

Please note that the indexing parameters are used only for entering the management decisions into the database (automatic filling by the program).

The record format includes, in this example:

- branch number in the form of a Roman numeral, $n=I$ and so on,

- index of degree of coverage - the general on the enterprise (branch) management decisions, they always begin with zero - 0 , the management decision on the functional area, in the table 8 functional areas are offered,

- index of the project (priority below the general on the branch), management decisions on the projects are numbered in order according to their number, the designation follows after the number of functional areas.

Such accounting allows you to record management decisions according to a hierarchy of importance and tracking. It is also possible to compare more and less successful project groups for ineffective management (by "packages" of management decisions).

If a management decision involves multiple functional areas and/or multiple projects, its numbering in the database depends on the features of the software environment, for example, it may look like: I52, which means the first branch, functional area "innovations", project No.2, if the management decision concerns two project groups, the index may look like I52_4, i.e. projects - No.2 and No.4.

It is possible to complement the index by a number and name assigned to each management decision. Then the full index of the considered management decision in the program can look like I52- No.17 "On the development of a new product".

\section{Factor model of controlling management decisions}

Each management decision is assigned the factors that affect its adoption and implementation.

The factors can be represented as a model (Fig. 2). 


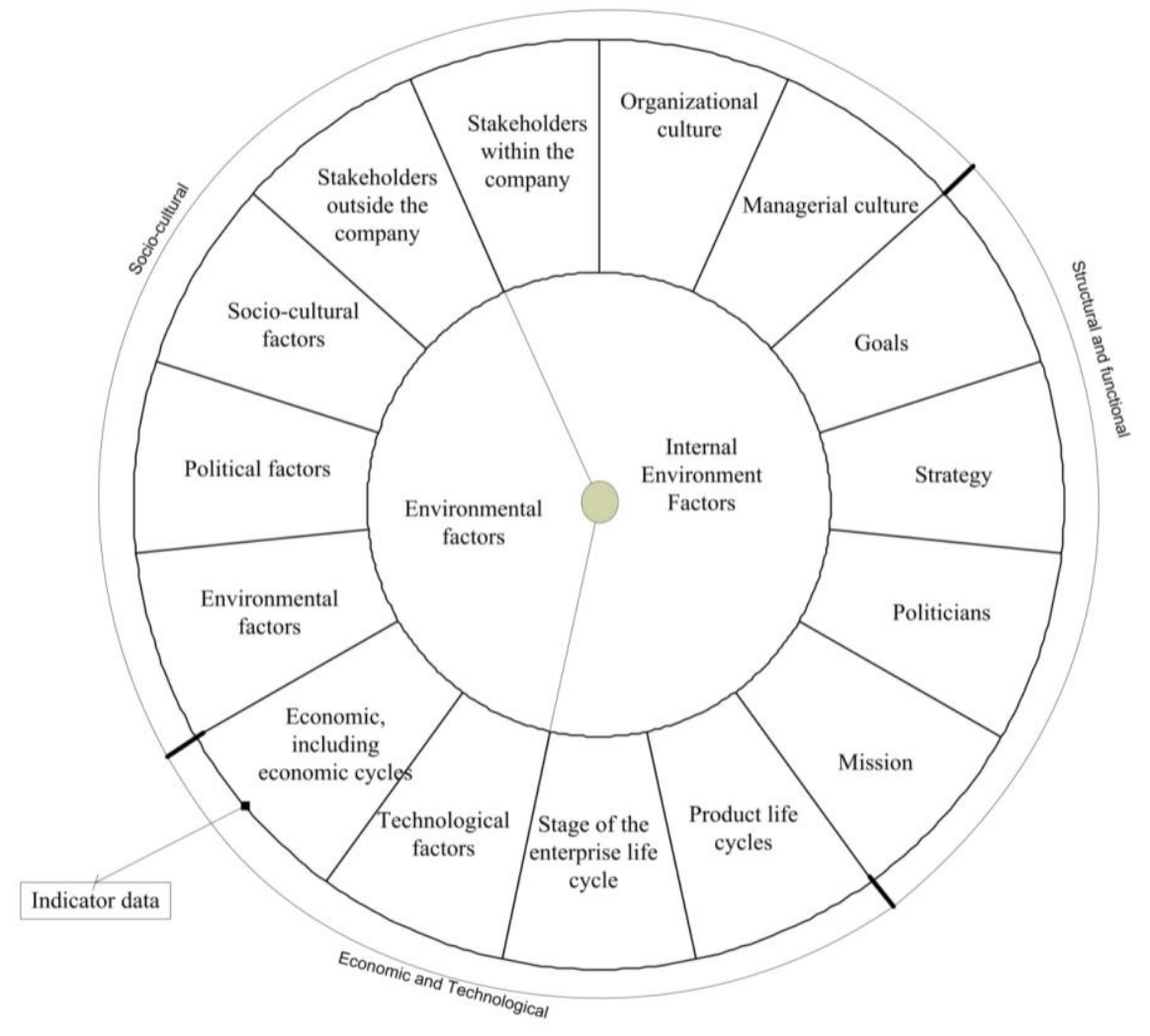

Fig. 2. Factor model.

Internal factors are organizational factors, external - environmental factors.

External factors include groups of factors traditionally studied in PESTE-analysis and Porter's 5 forces model. Internal factors include: organizational and managerial culture, mission, goals, strategy, various stakeholders within the enterprise.

The factors can be divided according to the nature of the influence: structural, sociocultural, economic and technological. Structural ones create target limitations in making management decisions, economic and technological ones are cyclic in nature and include macroeconomic cycles (world, country, branch cycles), and cycles at micro level - life cycle of enterprise and its products, socio-cultural ones characterize the stakeholders inside and outside the enterprise.

Figure 3 shows a conventional footnote to the data on the indicator by group of factors, it expresses a fragment of data bank, which should be formed throughout the enterprise according to the end-to-end principle, when each indicator collected by each subject is available to another subject (see table 2).

Table 2. Data for a particular indicator of the group of factors.

\begin{tabular}{|c|c|c|c|c|}
\hline \multirow{2}{*}{$\begin{array}{l}\text { Indicator } \\
\text { status }\end{array}$} & \multicolumn{4}{|c|}{ Time reference point } \\
\hline & t1 & $\mathbf{t 2}$ & t3 & tm \\
\hline Basic state & \multicolumn{4}{|l|}{ BS } \\
\hline Planned state & PS1 & PS2 & PS3 & PSm \\
\hline Actual state & AS1 & AS2 & AS3 & ASm \\
\hline
\end{tabular}


A typical table contains: baseline state - initial data of the indicator value at the time of management decision making, planned state - expected value of the indicator at a certain time checkpoint, actual state - actual value of the indicator at a given time checkpoint. Values may be both quantitative and qualitative.

This allows:

- promptly track changes in indicators,

- instantly restore information about the initial conditions of the management decision and its implementation,

- select certain factors and indicators from the centralized data bank to be linked to a specific management decision,

- if some factors are used for different types and levels of management decisions, there is no need to duplicate their analytics and information collection, all information is stored in one place.

This data bank is formed continuously, the data is updated, the implementation of the management decision takes into account the changing indicators of external and internal environment, creating an opportunity to adjust or completely change the process of implementation of the management decision.

Private information on the basis of the data bank on a particular management decision may take the form of a separate map, filled in part from the data bank (see Table 3).

Table 3. A typical example card of a management decision.

\begin{tabular}{|c|c|c|c|c|c|c|}
\hline \multicolumn{7}{|c|}{ I52- No.17 "On the development of a new product" } \\
\hline \multicolumn{7}{|c|}{ Block Project management decision } \\
\hline $\begin{array}{l}\text { The } \\
\text { Problem }\end{array}$ & \multicolumn{6}{|c|}{ Required information } \\
\hline Goal & \multicolumn{6}{|c|}{ Quantitative and qualitative objective } \\
\hline Cost & \multicolumn{6}{|c|}{ Quantity of the allocated resources } \\
\hline Content & \multicolumn{6}{|c|}{ What is a management decision } \\
\hline $\begin{array}{l}\text { Managemen } \\
\mathrm{t} \text { decision is } \\
\text { made by }\end{array}$ & \multicolumn{6}{|c|}{ Responsible (or group of persons) for making managerial decision } \\
\hline $\begin{array}{l}\text { Responsible } \\
\text { executor }\end{array}$ & \multicolumn{6}{|c|}{ Responsible (or group of persons) for implementation of management decision } \\
\hline $\begin{array}{l}\text { Date of } \\
\text { adoption }\end{array}$ & \multicolumn{6}{|c|}{ Date of adoption } \\
\hline $\begin{array}{l}\text { Expiration } \\
\text { date }\end{array}$ & \multicolumn{6}{|c|}{ Expected implementation date, duration of action } \\
\hline $\begin{array}{l}\text { Factors and } \\
\text { indicators }\end{array}$ & \multicolumn{6}{|c|}{$\begin{array}{l}\text { Data on the types of factors and their indicators, based on which the decision was } \\
\text { made }\end{array}$} \\
\hline \multicolumn{7}{|c|}{ Block Implementation of the management decision } \\
\hline \multirow[b]{2}{*}{ Time } & \multirow[b]{2}{*}{ 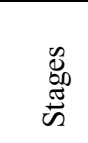 } & \multirow[b]{2}{*}{ Technology } & \multicolumn{2}{|l|}{ Value-plan } & \multicolumn{2}{|l|}{ Value-act } \\
\hline & & & $\begin{array}{l}\text { Implementatio } \\
\mathrm{n}\end{array}$ & $\begin{array}{l}\text { Factors: } \\
\text { indicator } \\
\mathrm{s}\end{array}$ & $\begin{array}{l}\text { Implementatio } \\
\mathrm{n}\end{array}$ & $\begin{array}{l}\text { Factors: } \\
\text { indicator } \\
\mathrm{s}\end{array}$ \\
\hline $\begin{array}{l}\text { Time } \\
\text { reference } \\
\text { point }\end{array}$ & $\begin{array}{l}\text { E् } \\
\text { Z̃ } \\
\text { Z }\end{array}$ & $\begin{array}{l}\text { Information on } \\
\text { implementatio } \\
n \text { technology }\end{array}$ & $\begin{array}{l}\text { Planned va } \\
\text { realization as } \\
\text { indicators imp } \\
\text { management de }\end{array}$ & $\begin{array}{l}\text { ue on } \\
\text { ell as on } \\
\text { ceting the } \\
\text { ision }\end{array}$ & $\begin{array}{l}\text { Actual } \\
\text { implementation } \\
\text { by indicators } \\
\text { management de }\end{array}$ & $\begin{array}{l}\text { as well as } \\
\text { as beting the } \\
\text { sion }\end{array}$ \\
\hline
\end{tabular}

The management decision map contains initial data - the "management decision project" block, and information on the life cycle of a management decision with a link to time points of control - the "implementation of a management decision" block. This allows you to track 
the correctness and success of the implementation of management decisions. The map contains indices, which influence efficiency of managerial decision and allow to estimate promptly correlation between these groups of values, and to take measures promptly, if it is necessary.

In the "realization" block it is possible to decompose a management decision not only into stages, but also into tasks, with a separate map of the same type being created for each of them.

\section{Matrix model of controlling management decisions}

In full volumetric form the matrix model of controlling of administrative decisions on the separate branch can have the following kind (fig. 3).

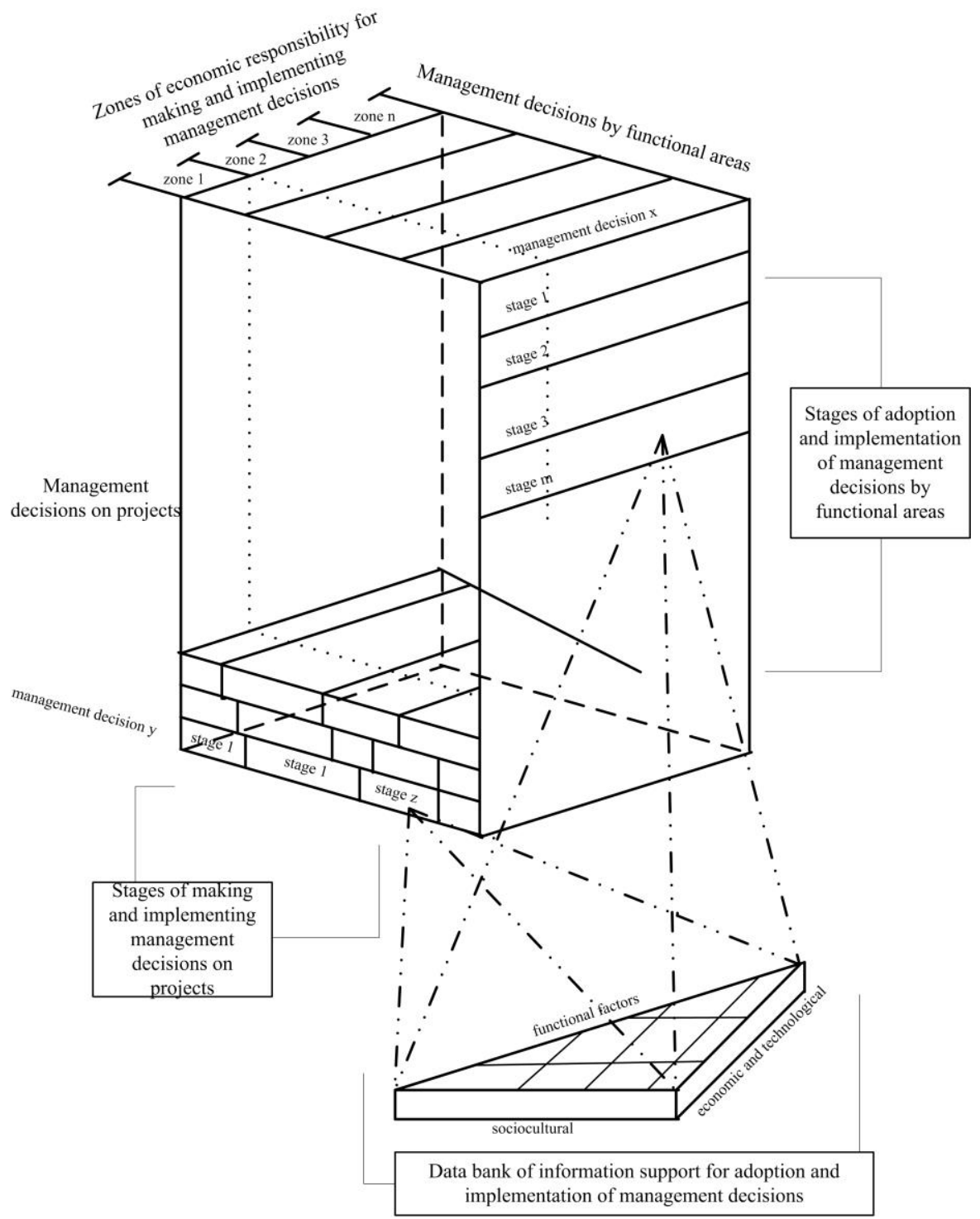

Fig. 3. Matrix model of controlling management decisions. 
The system of such structure provides transparency of vertical and horizontal management flows, makes it possible to assess their correlation with each other, at the same time establishes responsibility zones, covering different stages of making and realization of management decisions. All managerial decisions are provided with information support on the basis of data bank indicators. In turn, the data bank analyzes the cross-influence of factors and their indicators on each other.

The proposed information and software environment allows:

- form a database of management decisions and keep their centralized records,

- clearly distribute and determine the zones of influence of management decisions and their overlap,

- identify management decisions by branches, functional areas, and project groups,

- conduct end-to-end collection of necessary information across the entire enterprise in a single database,

- clearly present the original conditions of management decisions and updated data on the factors affecting the implementation,

- to control the implementation of any management decision, and the employees of the enterprise can independently evaluate the success of a particular management decision,

- the information and software environment allows to establish access zones to the information in the database of management decisions,

- decomposition of management decisions into tasks, maintaining a multilevel and hierarchical structure, and the ability to store all necessary information,

- due to the centralized collection and distribution of information on the factors of external and internal environment, duplication of data collection by other divisions of the enterprise is excluded, their work is simplified.

The creation of such an information system can significantly improve not only the adoption of management decisions and their implementation, but also streamline information flows, create a database of management decisions, control their life cycles and minimize the possibility of abuse and neglect among staff.

\section{References}

1. Khudyakova, T., Shmidt, A., Shmidt, S., Entrep. Sustain. Issues (2019) doi:10.9770/jesi.2019.7.2(27).

2. Rybicka, K., Usage of big data technology in controlling. Res. World Econ. (2019) doi:10.5430/rwe.v10n4p92.

3. Bieńkowska, A., Eng. Manag. Prod. Serv. (2020) doi:10.2478/emj-2020-0017.

4. Horváth, P., Gleich, R., Seiter, M., Controlling (2020)

5. Hahn, D., Hungenberg, H., PuK - Wertorientierte Controllingkonzepte (2001)

6. Vollmuth, J.H., Controlling instrumente, https://www.goodreads.com/book/show/38100546-controllinginstrumente

7. Luhmann, N., Barrett, R., Stehr, N., Bechmann, G., Risk: A sociological theory (2017) ISBN 9781351492911

8. Bieńkowska, A., Tworek, K., Zabłocka-Kluczka, A., Int. J. Digit. Account. Res. (2019) doi:10.4192/1577-8517-v19_1

9. Bieńkowska, A., Tworek, K., Zabłocka-Kluczka, A., Inf. Syst. Manag. (2020) doi:10.1080/10580530.2020.1696545 